\title{
À Jean Serroy
}

\section{Bernard Roukhomovsky}

\section{OpenEdition}

Journals

Édition électronique

URL : http://journals.openedition.org/recherchestravaux/250

DOI : 10.4000/recherchestravaux.250

ISSN : 1969-6434

\section{Éditeur}

UGA Éditions/Université Grenoble Alpes

\section{Édition imprimée}

Date de publication : 30 mai 2005

Pagination : 7-9

ISBN : 0151-1874

ISSN : 0151-1874

\section{Référence électronique}

Bernard Roukhomovsky, «À Jean Serroy », Recherches \& Travaux [En ligne], 67 | 2005, mis en ligne le 30 septembre 2008, consulté le 25 septembre 2020. URL : http://journals.openedition.org/ recherchestravaux/250; DOI : https://doi.org/10.4000/recherchestravaux.250

Ce document a été généré automatiquement le 25 septembre 2020

(C) Recherches \& Travaux 


\section{À Jean Serroy}

\section{Bernard Roukhomovsky}

\section{À Jean Serroy, \\ fin rieur et gai savant}

1 Puisque nous avons choisi, cher Jean Serroy, de placer cet hommage sous le signe du rire, je me plais à imaginer que quelque recueil de clefs tardivement découvert viendra nous confirmer ce que nous devinons : que le portrait qu'on vient de lire au seuil de ce volume est bien le vôtre. Et, le plus sérieusement du monde, je plaiderais volontiers pour l'attribution de ce texte à l'auteur des Caractères, n'était la difficulté chronologique qu'une telle hypothèse soulève, et l'extraordinaire longévité qu'elle reviendrait à vous prêter. Accordez-moi du moins qu'il fallait bien tout le génie d'un La Bruyère pour réussir à travailler d'après un modèle si redoutable, toujours prompt à échapper à qui s'efforce de le fixer.

2 Car ce n'est pas une petite affaire que d'attraper un pareil original. Que de natures, s'exclamerait un autre moraliste, en celle de cet homme-là! Et que de vacations! Professeur de littérature française (mais aussi d'histoire du cinéma) à l'université Stendhal, dix-septiémiste de classe internationale, journaliste et chroniqueur culturel dans un grand quotidien régional, historien du septième art, historien de la Drôme et du Dauphiné, très officiel arbitre des bonnes tables, publicitaire, auteur de guides touristiques et même, sous quelque nom d'emprunt, de romans policiers...

À l'instar de l'auteur fameux d'un fameux Pâté d'anguille, vous avez fait de la diversité votre devise : une diversité pleinement assumée qui ne tourne jamais à l'éparpillement, fermement sous-tendue qu'elle est par une certaine idée de la littérature, par une certaine idée de l'université, par un refus conscient de tous les formatages et de toutes les myopies, par une quête passionnée, en toute chose, grandes œuvres ou petits plats, de ces saveurs mêlées que vous débusquez savamment au fil de vos chroniques gourmandes ou de vos analyses critiques. Bref, on ne fait pas tenir en quelques mots les innombrables vies parallèles qui sont les vôtres, et je ne prétends pas ici le faire, quand bien même les parallèles finissent toujours par se rejoindre. 
Quelques constantes, cependant, peuvent être repérées. L'une d'elles s'appelle Grenoble. De fait, si l'audience internationale de vos travaux vous a valu de multiplier les séjours en qualité de professeur invité dans les universités du monde entier (de Boston à Tokyo, de Séoul à Turin, de Lisbonne à Vérone, de Vancouver à Cracovie...), c'est bien dans la capitale du Dauphiné que l'on vous retrouve tout au long de votre parcours, non loin de cette Drôme natale à laquelle, par ailleurs, vous êtes resté fidèle. C'est à Grenoble, en effet, précisément au lycée Emmanuel-Mounier que, jeune agrégé de Lettres classiques, vous faites vos débuts sur les estrades. Et puis, très vite, dès 1969, après un bref détour par la Savoie voisine, vous entrez, en qualité d'assistant de littérature française, dans cette maison dont vous allez devenir une sorte de mur porteur : vous y serez maître-assistant cinq ans plus tard, professeur en 1980, titulaire de la chaire de littérature française $d u$ XVII $^{\mathrm{e}}$ siècle, que vous occuperez, selon mes calculs, durant un quart de siècle. Il serait vain de vouloir résumer ce long chapitre, si nombreuses et si variées sont les fonctions que vous avez exercées au sein de cette institution (à commencer par la direction de la présente revue, de 1980 à 1993), si nombreux et si variés sont les enseignements que vous y avez dispensés (de l'histoire littéraire à l'écriture journalistique, pour ne rien dire du cinéma, déjà cité).

Il serait tout aussi ridicule de prétendre rendre compte, en quelques mots, de la foisonnante variété des objets de recherche dont vous vous êtes emparé, non sans un solide appétit et une évidente gourmandise, en bon vivant de la recherche (tant il est vrai que le chercheur, répétons-le, est en vous proche parent du gastronome). De fait, si la littérature du Grand Siècle - tous genres compris - n'a guère de secrets pour vous (comme le montre au besoin votre contribution protéiforme au nouveau "Grente »), vous en avez maintes fois traversé les frontières, multipliant les excursions vers d'autres territoires (de Maupassant à Brasillach, de Giono à De Gaulle...), comme vous avez plus d'une fois traversé celles de la littérature même, continûment soucieux de ressaisir le fait littéraire dans son rapport à tout cela dont il est tributaire (les arts, l'histoire, la politique...).

Une question, pourtant (et c'est une autre constante remarquable), tient dans votre œuvre de chercheur une place essentielle : celle des rapports - combien féconds! entre rire et littérature. Vaste sujet, dont la variété des études ici rassemblées révèle et reflète la richesse, et dont vous avez abordé de multiples facettes: du fou rire au sourire, des éclats de la place publique aux chatoiements de l'ironie, de Sorel à Molière... À travers ces gais travaux de gai savant, et singulièrement à travers votre thèse sur Les Histoires comiques au XVII e siècle (une de ces thèses, faut-il le rappeler, qui ont fait date, et qui figurent en bonne place dans la bibliothèque idéale de tout dixseptiémiste digne de ce nom), vous avez largement contribué, avec quelques autres, à changer pour ainsi dire la face du Grand Siècle et à nous la rendre plus riante, ou plus souriante, ce dont elle avait, soit dit en passant, le plus urgent besoin. Pour le dire autrement, vous nous avez appris à prendre au sérieux le rire (tous les rires) d'un siècle longtemps victime du dédain affiché par un certain Boileau pour le sac ridicule où Scapin s'enveloppe.

7 C'est à cette contribution décisive à l'histoire des rapports entre rire et littérature que nous avons souhaité rendre hommage plus particulièrement. Hommage au chercheur sans doute, mais à l'homme également, mais à l'homme avant tout. Car l'homme n'est pas moins habité que le chercheur par cette conviction qu'« il n'est rien de plus sérieux que le rire » (telle est la conclusion, cher Jean Serroy, de votre étude sur « Le rire dans 
Le Page disgracié »). Et de l'homme, je dirai volontiers (en adaptant très légèrement le texte que j'emprunte), ce que le chercheur (dans la même étude) écrivait au sujet du Page disgracié :

Ses talents de conteur, joints à un goût de l'amusement et à une certaine malice qu'il développe au contact des plus délurés de ses collègues, en font comme «l'intendant des divertissements » de la Faculté. 